\title{
Desempenho de híbridos de milho e da forrageira Brachiaria brizantha em cultivo consorciado
}

\section{Performance of corn hybrids and Brachiaria brizantha in intercropping}

\author{
Priscila Barcello Maia*, Iurhy da Silva Rezende, Flavio Heiji Tsumura
}

\begin{abstract}
Resumo: O estudo teve como objetivo avaliar o desempenho de híbridos simples de milho em consórcio com a forrageira (Brachiaria brizantha). O experimento foi conduzido no município de Cassilândia-MS utilizando delineamento experimental de blocos casualizados, com cinco repetições. Os tratamentos foram compostos por seis híbridos simples de milho: DKB390, BMX944, DKB399, P30F35H, P3862H e BM810. O milho foi plantado com semeadora mecanizada, no espaçamento de 0,90 m entrelinhas. A forrageira foi semeada a lanço aos 48 dias após semeadura do milho. Foram avaliados os parâmetros de componentes de produção dos híbridos de milho e da forrageira aos 117 dias após a semeadura do milho. Pelos resultados observados, o híbrido DKB399 apresentou melhor rendimento no cultivo em consórcio, sendo o mais indicado para o município de Cassilândia-MS.
\end{abstract}

Palavras-chave: Zea mays L., Forrageira, Produtividade, Genótipos

\begin{abstract}
The study aimed to evaluate the performance of simple hybrids of corn in consortium with forager (Brachiaria brizantha). The experiment was conducted in the municipality of Cassilândia-MS using experimental design of randomized blocks, with five repetitions. The treatments were composed of six simple hybrids of corn: DKB390, BMX944, DKB399, P30F35H, $\mathrm{P} 3862 \mathrm{H}$ and BM810. The corn was planted with mechanized seeder in $0.90 \mathrm{~m}$ spacing between lines. The forager was seeded to haul to 48 days after sowing the corn. We evaluated the parameters of production components of hybrids of maize and beans to 117 days after sowing the corn. By the results observed, the hybrid DKB399 presented best performance in cultivation in a consortium, being the most indicated for the municipality of Cassilândia-MS.
\end{abstract}

Key Words: Zea mays L., Forager, Productivity, Genotypes

\footnotetext{
*Autor para correspondência

Recebido em 25/02/2014 e aceito em 19/02/2015

*Universidade Estadual de Mato Grosso do Sul (UEMS). E-mail: priscilabarcello@ hotmail.com
} 


\section{INTRODUÇÃO}

Segundo Gonçalves e Franchini (2007), na década de 1970, em função dos grandes incentivos ao setor agropecuário, com linhas de crédito rural a juros baixos para custeio e investimentos, houve geração de riquezas e aumento da importância do Brasil no cenário mundial na produção de grãos e carnes. A partir da década de 1990, estas transformações contribuíram para novos mercados dentro do comércio internacional. Porém, apesar dos aspectos positivos a evolução deste cenário trouxe também consequências negativas sob o ponto de vista econômico e ambiental. Cita-se o manejo inadequado de solos e a ausência de adubação principalmente em pastagens, o uso intensivo de máquinas e implementos pesados no sistema de plantio convencional e a não utilização de sistemas conservacionistas, trazendo consequências ambientais como a degradação do solo e baixos índices de produtividade.

Atualmente, a prática do cultivo consorciado é considerada uma das melhores alternativas para a sustentabilidade dos sistemas agrícolas tropicais (BORGHI et al., 2013). Tais aumentos são resultado das alterações provocadas nas características químicas, físicas e biológicas do solo ao longo do tempo de adoção do sistema, melhorando o ambiente de produção em função de viabilizar cobertura morta para o SPD (GARCIA et al., 2008 ; CALONEGO et al., 2011).

Mesmo em cultivo consorciado, as espécies forrageiras proporcionam forragens em qualidade e quantidade suficiente para produção de pasto no período de outono-primavera e, por conseguinte, cobertura vegetal para o sistema plantio direto (KICHEL et al., 2009). Pariz et al. (2010) concluíram que o consórcio a lanço das forrageiras com a cultura do milho se mostrou viável por apresentar produtividade de massa seca semelhante às modalidades de semeadura exclusiva. De acordo com Freitas et al. (2005) a $U$. brizantha é excelente forrageira para ser utilizada no sistema de integração lavoura-pecuária (ILP), visando a formação de pasto e a diversificação da produção.

Segundo Alvarenga et al. (2008) para alcançar altas produtividades são necessários técnicas de manejo que aliadas ao potencial genético das variedades utilizadas estejam em consonância. Sendo assim, o rendimento de uma lavoura de milho é o resultado do potencial genético da semente e das condições edafoclimáticas do local de plantio, além do manejo correto da lavoura. De modo geral, a variedade é responsável por $50 \%$ do rendimento final, garantindo sucesso no sistema de consórcio. Consequentemente, a escolha correta da cultivar pode ser a razão do sucesso ou insucesso da lavoura (CRUZ et al., 2000).

Nos últimos anos, tem-se verificado um crescente aumento da disponibilidade de híbridos simples no mercado, sendo que na safra 2011/12 esse tipo de cultivar já representa mais de 60,32\% das sementes disponíveis EMBRAPA (2011). Assim, considerando-se as diferenças de ambiente e dos diferentes sistemas de produção, infere-se que é de interesse a avaliação de cultivares de milho, com o objetivo de subsidiar agricultores na escolha destes materiais (Carvalho et al., 2005).
Desse modo, o trabalho propõe avaliar o comportamento de seis híbridos de milho consorciado com B.brizantha no período de safra de verão, buscando alternativas para a produção de milho-grão, deixando o solo protegido e ainda, garantindo a formação de pastagem ou palhada após a colheita do milho.

\section{MATERIAL E MÉTODOS}

O experimento foi conduzido na safra 2011/12 em área experimental pertencente à Universidade Estadual do Mato Grosso do Sul (UEMS), Unidade Universitária de Cassilândia (UUC), situada a aproximadamente $19^{\circ} 06^{\prime}$ de latitude Sul e $51^{\circ} 04^{\prime}$ de longitude Oeste, com altitude de $471 \mathrm{~m}$. O clima se enquadra como Tropical Chuvoso (Aw) de acordo com a classificação climática de Köppen, com verão chuvoso e inverno seco. O solo da área experimental foi classificado como Neossolo Quartzarênico (EMBRAPA, 1999) apresentando as seguintes características químicas na camada de 0,0 a $0,20 \mathrm{~m}$ : $\mathrm{pH}$ em água de 4,90;2,60 $\mathrm{cmol}_{\mathrm{c}} \mathrm{dm}^{-3} \mathrm{de} \mathrm{H}+\mathrm{Al} ; 1 \mathrm{cmol}_{\mathrm{c}} \mathrm{dm}^{-3} \mathrm{de}$ $\mathrm{Ca} ; 0,70 \mathrm{cmol}_{\mathrm{c}} \mathrm{dm}^{-3} \mathrm{de} \mathrm{Mg} ; 4,70 \mathrm{cmol}_{\mathrm{c}} \mathrm{dm}^{-3}$ de CTC; 4,30 mg $\mathrm{dm}^{-3}$ de $\mathrm{P} ; 0,32 \mathrm{mmol}_{\mathrm{c}} \mathrm{dm}^{-3}$ de $\mathrm{K}$; e $19 \mathrm{~g} \cdot \mathrm{dm}^{-3}$ de matéria orgânica e saturação por base de $44,90 \%$.

A área experimental, cultivada anteriormente com $B$. brizantha, foi dessecada com o herbicida sistêmico glyphosate, na dose de $1.800 \mathrm{~g} \mathrm{ha}^{-1}$. O preparo de solo foi realizado 15 dias após a dessecação, por meio de uma aração, duas gradagens pesada e gradagem niveladora, com aplicação de calcário dolomítico (PRNT 90\%) para elevação da saturação por bases a $70 \%$ de acordo com as doses estabelecidas.

$\mathrm{O}$ delineamento experimental utilizado foi $\mathrm{o}$ de blocos casualizados, com cinco repetições. Os tratamentos foram compostos por seis híbridos simples de milho: DKB390, BMX944, DKB399, P30F35H, P3862H, BM810. Cada unidade experimental foi constituída por oito linhas de dez metros de comprimento, espaçadas em $0,90 \mathrm{~m}$, perfazendo uma área total de $80 \mathrm{~m}^{2}$. A semeadura do milho foi realizada em 04/12/2011 com semeadora de discos lisos, visando obter uma população 62.221 plantas ha $^{-1}$. No plantio foi realizado aplicação de 270 $\mathrm{kg} \mathrm{ha}^{-1}$ da formulação 5-37-00 (N-P-K) e $109 \mathrm{~kg} \mathrm{ha}^{-1}$ de N, em cobertura aos 15 dias após o plantio (DAP). A fonte de $\mathrm{N}$ utilizada na adubação de cobertura foi o sulfato de amônio (520 $\mathrm{kg} \mathrm{ha}^{-1}$ ) conforme as recomendações de Cantarella et al. (1996). Como tratamento fitossanitário, utilizou-se, aos 34 dias após a emergência do milho (DAE) o inseticida Imunit ${ }^{\circledR}$ na dose de $160 \mathrm{ml} \mathrm{ha}{ }^{-1}$, visando o controle da lagarta-do-cartucho (Spodoptera frugiperda). A aplicação foi realizada com auxilio do pulverizador costal manual, bico cone, com vazão da calda de 300 $\mathrm{La}^{-1}$. Aos 48 DAP foi realizada a semeadura a lanço da forrageira, na densidade de $12 \mathrm{~kg} \mathrm{ha}^{-1}$ de sementes viáveis $(35 \%$ $\mathrm{VC})$.

O milho foi colhido manualmente aos 117 DAP e em pré-colheita avaliaram-se na área útil da parcela (três linhas centrais): estande final através da contagem de plantas; número de espigas por planta; altura de plantas pela determinação da distância da superfície do solo até a inserção da ultima folha completamente expandida $(\mathrm{cm})$; diâmetro do colmo com o uso de um paquímetro, medido na base da planta $(\mathrm{mm})$. Após a 
colheita, foram retiradas dez espigas de cada parcela para tomada dos dados: número de grãos por espiga; massa de grãos por espiga sendo o número de grãos dividido pelo número de espigas; massa da espiga com palha e sem palha através da pesagem em balança analítica eletrônica; peso das sementes através da massa das sementes dividido pelo número de sementes e rendimento de grãos. A massa seca da forrageira $B$. brizantha, foi avaliada após a colheita do milho, através de três amostragens em cada parcela com quadro de $0,5 \times 0,5 \mathrm{~m}$. A forragem coletada, foi acondicionada em sacos previamente identificados para pesagem. Em seguida, o material foi posteriormente levado para estufa com ventilação forçada, a $65^{\circ} \mathrm{C}$, até atingir massa constante, sendo, posteriormente, determinada a massa seca.

Os resultados foram submetidos à análise de variância e quando os efeitos de tratamentos foram significativos $(p<0,05)$ realizou-se a comparação de médias pelo teste de Tukey a 5\% de probabilidade, utilizando o programa estatístico SISVAR ${ }^{\circledR}$ (FERREIRA, 1999).

\section{RESULTADOS E DISCUSSÃO}

Verificou-se efeito significativo $(\mathrm{p}<0,05)$ nas variáveis: estande final de plantas, altura de plantas, altura de inserção da primeira espiga, número de espigas e rendimento de grãos. Já as variáveis diâmetro de colmos, massa de espiga com palha e número de grãos por espiga não foram estatisticamente diferentes. $\mathrm{O}$ rendimento de massa seca da forrageira $B$. brizantha, não sofreu alterações significativas na presença dos diferentes híbridos de milho (Tabela 1). Com relação aos coeficientes de variação (CV\%), houve boa precisão na condução do experimento para a maioria dos componentes de produção avaliados, com exceção para a massa de espiga com e sem palha, número de grãos por espiga, rendimento de grãos e massa seca da forrageira, sendo maior que $10 \%$ (PIMENTEL GOMES, 1990).

Observando o estande final de plantas, o híbrido DKB399 obteve o melhor desempenho com densidade de plantas de 54.400 plantas ha $^{-1}$, enquanto que o híbrido BM810 foi o que apresentou o menor estande final de plantas com 44.400 plantas $\mathrm{ha}^{-1}$. As maiores densidade de plantas encontradas podem indicar o bom desempenho do híbrido em condições de menor espaçamento, fator não testado no presente estudo. De acordo com Freitas et al. (2013) a maior densidade de plantas proporciona maior produção por área e redução na produtividade por indivíduo. Este comportamento pode determinar o rendimento de grãos conforme descreve Almeida
\& Sangoi (1996). Segundo os autores, o estande pode afetar a arquitetura das plantas, alterando o crescimento e o desenvolvimento das plantas de milho.

Houve diferença significativa para a altura de inserção da primeira espiga. O híbrido BM810 apresentou as menores alturas de inserção, diferindo os outros híbridos que apresentaram maiores valores para esta variável. Os resultados encontrados neste trabalho corroboram alguns estudos (MEROTTO JUNIOR et al., 1997; SANGOI, 2001; SANGOI et al., 2002), relatando que pode ocorrer dominância apical em condições com maiores densidades populacionais. Para Marchão et al. (2005), esse maior crescimento foi representado pela maior altura de inserção das espigas, provavelmente se deve à competição por luz.

A altura de plantas foi diferente entre os híbridos. As maiores alturas de plantas foram observadas nos híbridos $30 \mathrm{~F} 35 \mathrm{H}$ e $\mathrm{P} 3862 \mathrm{H}$ com $1,97 \mathrm{~m}$ e $1,95 \mathrm{~m}$ respectivamente, superando os resultados obtidos por CRUZ et al. (2009) que obteve 1,89 m para o híbrido 30F35H. O híbrido DKB399, este apresentou uma altura intermediaria de $1,81 \mathrm{~m}$, sendo inferior a média alcançada no experimento conduzido por Hanashiro et al. (2013) com altura de $2,57 \mathrm{~m}$. Tais diferenças em relação ao trabalho atual podem estar relacionadas a fatores de diferentes disponibilidade de recursos ambientais, como água, luz e nutrientes. A redução na altura de plantas foi mais acentuada para o híbrido BM810, com 1,55 m. Plantas de milho com estatura média a baixa permitem maior eficiência na colheita mecânica devido à redução da ocorrência de quebra e acamamento, e toleram maiores densidades populacionais de plantas, mantendo a uniformidade das espigas (SÁ, 1993; MIRANDA et al., 2003; BRACHTVOGEL et al., 2009).

Os resultados de diâmetro do colmo mostraram valor médio de 10,42 $\mathrm{mm}$, porém não apresentaram diferenças significativas entre os diferentes híbridos avaliados, não comprometendo desta forma, a formação e o acúmulo de reservas nos colmos. O diâmetro do colmo apresenta correlação com o rendimento, por se tratar de um órgão de reserva da planta (CRUZ et al., 2008), que serão utilizados posteriormente na formação dos grãos. Segundo Tsumanuma (2004), o diâmetro do colmo é uma estrutura destinada ao armazenamento de sólidos solúveis para situações emergenciais, e quanto maior for seu diâmetro, maior será sua capacidade de armazenamento de fotoassimilados, contribuindo consideravelmente para a formação de grãos. No trabalho, os híbridos não manifestaram indicativos que permitissem observar os melhores neste componente de produção.

Tabela 1. Estande final de plantas (EFP), altura de plantas (AP), altura de inserção da primeira espiga (AIE) e diâmetro de colmos (DC) no sistema de consorciação de milho com a forrageira Brachiaria brizantha cv. Marandu em Cassilândia - MS, safra 2011/12.

\begin{tabular}{ccccc}
\hline Híbridos & EFP $\left(\mathrm{Pl} \mathrm{ha}^{-1}\right)$ & AP $(\mathrm{m})$ & AIE $(\mathrm{m})$ & DC $(\mathrm{mm})$ \\
\hline DKB390 & $52.400 \mathrm{ab}$ & $1,66 \mathrm{bc}$ & $0,87 \mathrm{a}$ & $17,81 \mathrm{a}$ \\
BMX944 & $48.000 \mathrm{ab}$ & $1,65 \mathrm{bc}$ & $0,78 \mathrm{a}$ & $16,61 \mathrm{a}$ \\
DKB399 & $54.400 \mathrm{a}$ & $1,81 \mathrm{ab}$ & $0,88 \mathrm{a}$ & $15,48 \mathrm{a}$ \\
$30 F 35 \mathrm{H}$ & $52.400 \mathrm{ab}$ & $1,97 \mathrm{a}$ & $0,82 \mathrm{a}$ & $17,36 \mathrm{a}$ \\
P3862H & $49.000 \mathrm{ab}$ & $1,95 \mathrm{a}$ & $0,87 \mathrm{a}$ & $16,74 \mathrm{a}$ \\
BM810 & $44.400 \mathrm{c}$ & $1,55 \mathrm{c}$ & $0,60 \mathrm{~b}$ & $15,48 \mathrm{a}$ \\
\hline CV $(\%)$ & 8,98 & 6,76 & 10,07 & 10,42 \\
\hline
\end{tabular}

* Médias seguidas de mesma letra, na coluna, não diferem pelo teste de Tukey ao nível de 5\% de probabilidade 
Na tabela 2 são apresentados os valores médios de número de espigas por planta, onde se observa que o híbrido DKB399 respondeu de forma positiva nesse componente, com o aumento do número de espigas. Resultados semelhantes foram encontrados para os demais, com exceção do híbrido BM810 que apresentou o menor índice de espiga. Segundo Sangoi et al. (2000), plantas espaçadas equidistantemente competem menos por nutrientes, luz e outros fatores, favorecendo o melhor desenvolvimento das espigas.

Em relação à massa de espiga sem palha, houve maior índice para o híbrido DKB390, sendo que os demais apresentaram comportamento semelhante com valores intermediários. Já o híbrido BM810 apresentou os menores valores. Segundo Vallejos Mernes (1998), esses resultados podem estar relacionados com o florescimento antecipado das plantas de milho e as melhores condições climáticas para o estabelecimento e posterior desenvolvimento da cultura, proporcionando maior massa das espigas. Com relação à massa de espiga com palha, não se verificou diferença entre os híbridos utilizados neste sistema de cultivo.
O número de grãos por espiga, não apresentou diferença entre os híbridos avaliados, podendo-se observar que os valores para o $30 \mathrm{~F} 35 \mathrm{H}$ foram superiores, tendo alcançado um máximo de 505 grãos por espiga, na população de 62.221 plantas $\mathrm{ha}^{-1}$. No trabalho realizado por Demétrio et al. (2008), até população de plantas de 55.000 plantas ha $^{-1}$ houve aumento do número de grãos na primeira espiga. A partir dessa população, o aumento da densidade populacional provocou a diminuição desse componente, indicando crescente competitividade por fotoassimilados, que são necessários para o crescimento reprodutivo, segundo Bruns \& Abbas (2005).

Dentre os caracteres avaliados nas espigas, somente $o$ número de fileira de grãos por espiga, não variou em função dos híbridos utilizados. Segundo Marchão et al. (2005) a explicação pode estar relacionada ao fato de que o potencial de produção é definido, no primeiro estágio de desenvolvimento, quando ocorre o início do processo de diferenciação floral e a formação dos primórdios da panícula e da espiga, não havendo ainda uma influencia significativa da competição por plantas no ambiente.

Tabela 2. Número de espigas (EP) por planta, massa de espigas com palha (MECP), massa de espigas sem palha (MESP), número de grãos por espiga (NGE) e o número de fileiras de grãos (NFG) no sistema de consorciação de milho com a forrageira Brachiaria cv. Marandu. UEMS, Cassilândia - MS, safra 2011/12

\begin{tabular}{lccccc}
\hline \multicolumn{1}{c}{ Híbridos } & $\begin{array}{c}\text { EP } \\
\text { (unid.) }\end{array}$ & $\begin{array}{c}\text { MECP } \\
(\mathrm{kg})\end{array}$ & $\begin{array}{c}\text { MESP } \\
(\mathrm{kg})\end{array}$ & $\begin{array}{c}\text { NGE } \\
(\text { unid.) }\end{array}$ & $\begin{array}{c}\text { NFG } \\
\text { (unid.) }\end{array}$ \\
\hline DKB390 & $48220 \mathrm{ab}$ & $5,91 \mathrm{a}$ & $5,40 \mathrm{a}$ & $479,26 \mathrm{a}$ & $15 \mathrm{a}$ \\
BMX944 & $45560 \mathrm{ab}$ & $4,90 \mathrm{a}$ & $3,85 \mathrm{ab}$ & $461,21 \mathrm{a}$ & $15 \mathrm{a}$ \\
DKB399 & $53400 \mathrm{a}$ & $5,80 \mathrm{a}$ & $5,13 \mathrm{ab}$ & $494,78 \mathrm{a}$ & $14 \mathrm{a}$ \\
30F35H & $51600 \mathrm{ab}$ & $5,44 \mathrm{a}$ & $4,47 \mathrm{ab}$ & $505,28 \mathrm{a}$ & $16 \mathrm{a}$ \\
P3862H & $47800 \mathrm{ab}$ & $5,87 \mathrm{a}$ & $4,81 \mathrm{ab}$ & $433,02 \mathrm{a}$ & $13 \mathrm{~b}$ \\
BM 810 & $41000 \mathrm{c}$ & $3,89 \mathrm{a}$ & $3,37 \mathrm{bc}$ & $456,14 \mathrm{a}$ & $16 \mathrm{a}$ \\
\hline CV (\%) & 11,31 & 20,47 & 20,13 & 12,13 & 5,73 \\
\hline
\end{tabular}

* Médias seguidas de mesma letra, na coluna, não diferem pelo teste de Tukey ao nível de 5\% de probabilidade

Na tabela 3, são apresentados os resultados de massa seca da parte aérea de $B$. brizantha e rendimento de grãos, no sistema de consorciação de milho com a forrageira. No entanto, observou-se efeitos significativos apenas para rendimento de grãos, o que pode ser atribuído a diversos fatores, entre os quais se pode citar o tipo de híbrido, população de plantas, as características climáticas da região, o nível de fertilidade do solo, entre outros (SANGOI et al., 2002). O maior rendimento de grãos foi encontrado no híbrido DKB399 alcançando maiores valores com $5.702 \mathrm{~kg} \mathrm{ha}^{-1}$. Com exceção do híbrido BM810 que apresentou o menor rendimento de grãos, acarretando em uma diferença significativa de $3.760 \mathrm{~kg} \mathrm{ha}^{-1}$ quando comparado ao híbrido de maior rendimento. Este fator pode ser atribuído à quebra do sincronismo entre emissão dos estigmas e liberação do pólen, justificando a ocorrência de espigas com poucos grãos (BERGAMASCHI et al., 2004).

A produção de massa seca da forrageira não diferiu entre os híbridos de milho, destacando a produção de massa seca entre 2.381,76 a 4.194,00 $\mathrm{kg} \mathrm{ha}^{-1}$, indicando que a consorciação não exerceu efeito sobre estas variáveis. Houve tendência dos maiores rendimentos de grãos estarem correlacionados com a menor presença de massa seca da forrageira. Cobucci (2001) comenta que a ausência da diferença estatística para estas variáveis, em consórcios de milho com Brachiaria spp., em semeadura simultânea, pode ser explicada pelo fato de as braquiárias apresentarem crescimento inicial lento, não interferindo, desta forma, sobre o desenvolvimento do milho. Este resultado se mostra favorável no que relata Cruz et al. (2008), visto que é desejável até a fase de desenvolvimento do milho, uma produção de massa não tão expressiva da forrageira, com menor competição à cultura produtora de grãos. Outras variáveis como a massa de espigas, é relacionada também por Dourado Neto et al. (2003). De acordos com os autores, o aumento da população da forrageira é devido à competição intra e interespecífica entre as espécies consorciadas, principalmente na fase crítica de desenvolvimento do milho, o que estimula a dominância apical, aumentando a esterilidade feminina e limitando a produção de grãos por área. 
Tabela 3. Rendimento de grãos (RG) e massa seca da parte aérea (MSPA), no sistema de consorciação de milho com a forrageira Brachiaria cv. Marandu. UEMS, Cassilândia - MS, safra 2011/12

\begin{tabular}{lcc}
\hline Híbridos & $\begin{array}{c}\text { RG } \\
\left(\mathrm{Kg} \mathrm{ha}^{-1)}\right.\end{array}$ & $\begin{array}{c}\text { MSPA } \\
\left(\mathrm{Kg} \mathrm{ha}^{-1)}\right.\end{array}$ \\
\hline DKB390 & $5.219,10 \mathrm{ab}$ & $2.846,72 \mathrm{a}$ \\
BMX944 & $3.929,00 \mathrm{~b}$ & $3.318,24 \mathrm{a}$ \\
DKB399 & $5.702,60 \mathrm{a}$ & $2.381,76 \mathrm{a}$ \\
30 35H & $4.515,60 \mathrm{ab}$ & $3.527,36 \mathrm{a}$ \\
P3862H & $5.271,80 \mathrm{ab}$ & $3.530,56 \mathrm{a}$ \\
BM810 & $1.942,60 \mathrm{c}$ & $4.194,00 \mathrm{a}$ \\
\hline CV $(\%)$ & 18,14 & 47,61 \\
\hline
\end{tabular}

* Médias seguidas de mesma letra, na coluna, não diferem pelo teste de Tukey ao nível de $5 \%$ de probabilidade

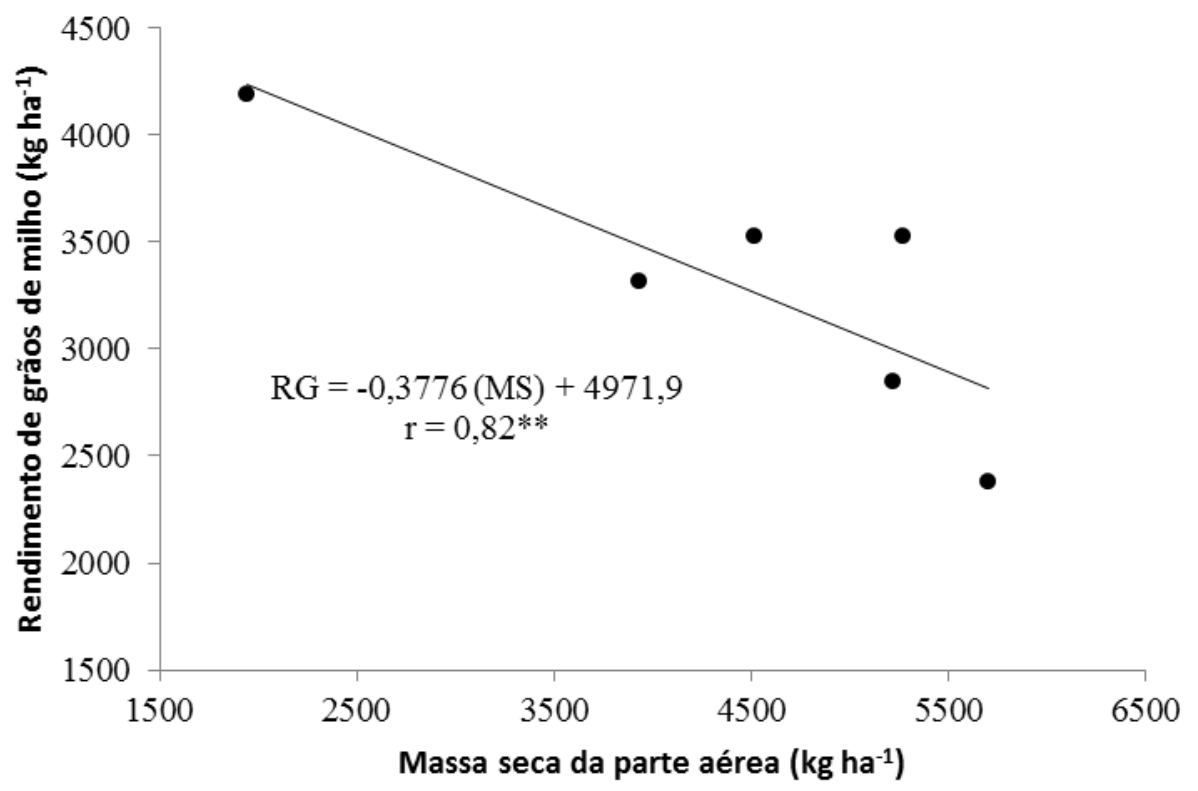

Figura 1. Correlação entre o Rendimento de grãos (RG) e massa seca da parte aérea (MSPA), no sistema no sistema de consorciação de milho com a forrageira Brachiaria cv. Marandu. UEMS, Cassilândia - MS, safra 2011/12

De forma geral, evidenciou-se viabilidade na formação de pastos em consórcio com a cultura do milho. Assim, têm-se o melhor aproveitamento de uso do solo, sem redução do rendimento do milho bem como das forrageiras. Esta modalidade de cultivo pode ser promissora para pequenos e grandes produtores, por consistir em uma tecnologia simples e acessível.

\section{CONCLUSÃO}

O híbrido DKB399 apresenta os melhores índices de desempenho agronômico, sendo o mais indicado para a região em consórcio com Brachiaria brizantha.

A produção de massa seca da forrageira e o rendimento de grãos de milho em sistema consorciado são dependentes.

\section{REFERÊNCIAS BIBLIOGRÁFICAS}

Alvarenga, R. C. et al. A Cultura do Milho na integração Lavoura-Pecuária. In: CRUZ, J. C. et al. (Ed.). A Cultura do Milho. Sete Lagoas: Embrapa Milho e Sorgo, p.491$517,2008$.

Bergamaschi, H.; Dalmago, G.A.; Bergonci, J.I.; Bianchi, C.A.M.; Müller, A.G.; Comiran, F.; Heckler, B.M.M. Distribuição hídrica no período crítico do milho e produção de grãos. Pesquisa Agropecuária Brasileira, v.39, p.831$839,2004$.

Borghi, E.; Crusciol, C. A. C.; Mateus, G. P.; Nascente, A. S.; Martins, P. O. intercropping time of corn and palisadegrass or guineagrass affecting grain yield and forage production. Crop Science, v. 53, p. 629-636, 2013.

Brachtvogel, E. L.; Pereira, F. R. S.; Cruz, S. C. S.; Bicudo, S. J. Densidades populacionais de milho em arranjos espaciais convencional e eqüidistante entre plantas. Ciência Rural, Santa Maria, v. 39, n. 8, p. 2334-2339, 2009. 
Bruns, H.A.; Abbas, H.K. Ultra-high plant populations and nitrogen fertility effects on corn in the Mississippi valley. Agronomy Journal, v.97, p.1136-1140, 2005.

Calonego, J. C.; Poleto, L. C.; Domingues, F. N.; Tiritan, C. S. Produtividade e crescimento de milho em diferentes arranjos de plantas. Revista Agrarian, Dourados, v. 4, n. 12, p.84-90, 2011.

Carvalho, H.W.L.; Cardoso, M.J.; Leal, M.L.S.; Santos, M.X.; Tabosa, J.N.; Souza, E.M. Adaptabilidade e estabilidade de cultivares de milho no Nordeste brasileiro. Pesquisa Agropecuária Brasileira, v.40, n.5, p.471-477, 2005.

Cobucci, T. Manejo integrado de plantas daninhas em sistema de plantio direto. In: Zambolim, L. Manejo Integrado Fitossanidade: cultivo protegido, pivô central e plantio direto. Viçosa: UFV, p.583-624, 2001.

Cruz, J. C.; Perreira Filho, I. A.; Gama, E. E. G. e; Pereira, F. T. F.; Corrêa, L. A. Cultivares de milho no mercado de sementes de milho no Brasil no ano 2000. Embrapa Milho e Sorgo. Documento Técnico, 4. Sete Lagoas: Embrapa Milho e Sorgo, 2000. 33 p.

Cruz, S.C.S.; Pereira, F.R.S.; Santos Júnior; Albuquerque, A.W.; Pereira, R.G. Adubação nitrogenada para o milho cultivado em sistema plantio direto, no Estado de Alagoas.

Revista Brasileira Engenharia Agrícola e Ambiental, Campina Grande, v.12, n.1, p.62-68, 2008.

Cruz, S. C. S.; Pereira, F. R. da S.; Bicudo, S. J.; Santos, J. R.; Albuquerque, A. W. de; Machado, C. G. Consórcio de milho e Brachiaria decumbens em diferentes preparos de solo. Acta Scientiarum: agronomy, Maringá, v. 31, n. 4, p. 633-639, 2009.

Demétrio, C. S.; Fornasieri Filho, D.; Cazetta, J. O.; Cazetta, D. A. Desempenho de híbridos de milho submetidos a diferentes espaçamentos e densidades populacionais. Pesquisa Agropecuária Brasileira, v. 43, n. 12, p.1691-1697, 2008.

Dourado Neto, D.D.; Palhares, M.; Vieira, P.A.; Manfron, P.A.; Medeiros, S.L.P.; Romano, M.R. Efeito da população de plantas e do espaçamento sobre a produtividade de milho. Revista Brasileira de Milho e Sorgo, v.2, n. 12, p.63-77, 2003.

Embrapa Milho e Sorgo: Cultivo do Milho. Disponível em: < http://www.cnpms.embrapa.br/publicacoes/milho_7_ed/cul tivares.htm>. Acesso em 20 jan. 2014.

Ferreira, D. F. Sistema de análise de variância (Sisvar). versão 4.6. Lavras: Universidade Federal de Lavras, 1999. CD-ROM.
Freitas, F. C. L.; Ferreira, L. R.; Ferreira, F. A.; Santos, M. V.; Agnes, E. L.; Cardoso, A. A.; Jakelaitis, A. Formação de pastagem via consórcio de Brachiaria brizantha com o milho para silagem no sistema de plantio direto. Planta Daninha, Viçosa, v. 23, n. 1, p.49-58, 2005.

Garcia, R. A.; Crusciol, C. A. C.; Calonego, J. C.; Rosolem, C. A. Potassium cycling in a corn-brachiaria cropping system. European Journal of Agronomy, Montpellier, v. 28, n. 4, p.579-585, 2008.

Gonçalves, S.A.; Franchini, J.C. Integração lavoura-pecuária. Londrina: Embrapa Soja, 2007. 8p. (Embrapa Soja. Circular técnica, 44).

Kichel, A. N.; Costa, J. A. A.; Almeida, R. G. de. Cultivo simultâneo de capins com milho safrinha: produção de grãos, de forragem e de palhada para plantio direto. Campo Grande: Embrapa Gado de Corte, 2009. 24 p. (Embrapa Gado de Corte. Comunicado técnico. Documentos, 177).

Marchão, R. L. Brasil, E. M.; Duarte, J. B.; Guimarães, C. M.; Gomes, J. A. Densidade de plantas e características agronômicas de híbridos de milho em espaçamento reduzido entre linhas. Pesquisa Agropecuária Tropical, Goiânia, v. 35, n. 2, p.93-101, 2005.

Merotto Júnior, A.; Almeida, M.L.; Fuchs, O. Aumento no rendimento de grãos de milho através do aumento da população de plantas. Ciência Rural, Santa Maria, v. 27, n. 4, p.549-554, 1997.

Miranda, G. V.; Coimbra, R. R.; Godoy, C. L.; Souza, L. V.; Guimarães, L. J. M.; Melo, A. V. Potencial de melhoramento e divergência genética de cultivares de milho-pipoca. Pesquisa Agropecuária Brasileira, Brasília, v. 38, n. 6, p.681-688, 2003.

Pariz, C. M.; Andreotti, M.; Azenha, M. V.; Bergamaschine, A. F.; Mello, L. M. M.; Lima, R. C. Massa seca e composição bromatológica de quatro espécies de braquiárias semeadas na linha ou a lanço, em consórcio com milho no sistema plantio direto na palha. Acta Scientiarum Animal Sciences, Maringá, v. 32, n. 2, p. 147-154, 2010.

Pimentel-Gomes, F. Curso de estatística experimental. 13.ed. Piracicaba: Nobel, 1990. 468p.

Sá, J. C. M. Sistema de produção de milho visando alta produtividade na região dos campos gerais no centro-sul do Paraná. In: Büll, L. T; Cantarella, H. (Ed.). Cultura do milho: fatores que afetam a produtividade. Piracicaba: POTAFÓS, 1993. 301p.

Sangoi, L. Understanding plant density effects on maize growth and development: an important issue to maximize grain yield. Ciência Rural, Santa Maria, v.31, n.1, p.159-168, 2001. 
Sangoi, L.; Almeida, M. L.; Gracietti, M. AM.; Bianchet, P.; Horn, D. Sustentabilidade do colmo em híbridos de milho de diferentes épocas de cultivo em função da densidade de plantas. Revista de Ciências Agroveterinárias, Lages, n. 2,2002 .

Sangoi, L.; Ender, M.; Guidolin, A.F.; Bogo, A.; Kothe, D.M. Incidência e severidade de doenças de quatro híbridos de milho cultivados com diferentes densidades de plantas. Ciência Rural, v.30, p.17-21, 2000.

Tsumanuma, G. M. Desempenho do milho consorciado com diferentes espécies de braquiárias, em Piracicaba, SP. Piracicaba: Escola Superior de Agricultura Luiz de Queiroz, 2004, 100 f. Dissertação (Mestrado em Agronomia, Fitotecnia).

Vallejos Mernes, F.J. Influência de sistemas de preparo de solo em algumas propriedades químicas e físicas de um Podzólico Vermelho-Amarelo Câmbico, Argiloso, e na cultura do trigo (Triticum aestivum L.). Viçosa, 1998. 81p. Dissertação (Mestrado) - Departamento de Fitotecnia, Universidade Federal de Viçosa. 